\title{
Counselors' Experience with Disaster Survivors of Natural Disasters: A Descriptive Phenomenological Study
}

Mohd. Zaliridzal Zakaria, Noor Syamilah Zakaria, Dini Farhana Baharudin, Steven Eric Krauss, Zainal Madon, Neerushah Subarimaniam

To Link this Article: http://dx.doi.org/10.6007/IJARBSS/v11-i8/10690

DOI:10.6007/IJARBSS/v11-i8/10690

Received: 21 June 2021, Revised: 24 June 2021, Accepted: 12 July 2021

Published Online: 28 August 2021

In-Text Citation: (Zakaria et al., 2021)

To Cite this Article: Zakaria, M. Z., Zakaria, N. S., Baharudin, D. F., Krauss, S. E., Madon, Z., \& Subarimaniam, N. (2021). Counselors' Experience with Disaster Survivors of Natural Disasters: A Descriptive Phenomenological Study. International Journal of Academic Research in Business and Social Sciences, 11(8), 1419-1438.

\section{Copyright: @ 2021 The Author(s)}

Published by Human Resource Management Academic Research Society (www.hrmars.com)

This article is published under the Creative Commons Attribution (CC BY 4.0) license. Anyone may reproduce, distribute, translate and create derivative works of this article (for both commercial and non-commercial purposes), subject to full attribution to the original publication and authors. The full terms of this license may be seen at: http://creativecommons.org/licences/by/4.0/legalcode

Vol. 11, No. 8, 2021, Pg. 1419 - 1438 


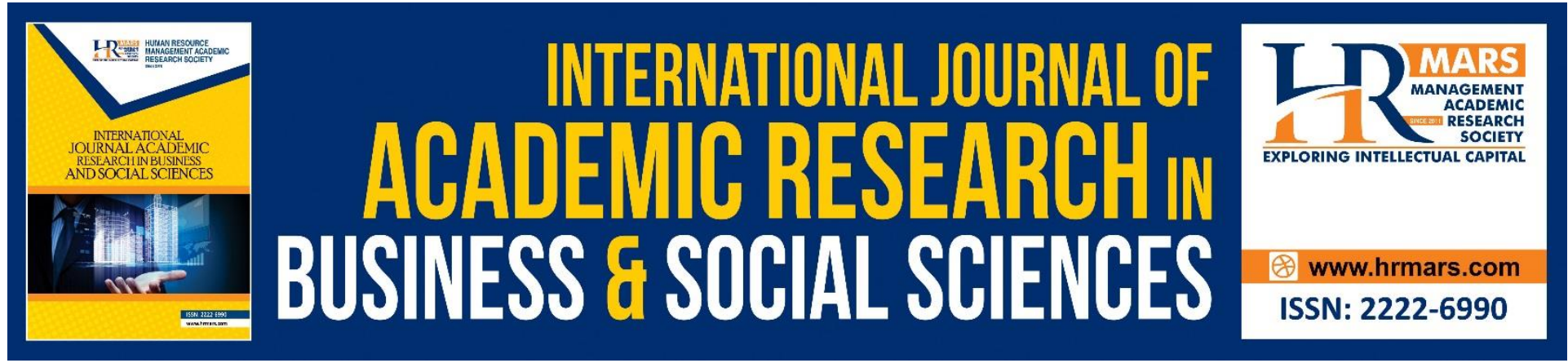

\title{
Counselors' Experience with Disaster Survivors of Natural Disasters: A Descriptive Phenomenological Study
}

\author{
Mohd. Zaliridzal Zakaria \\ Counseling Program, Universiti Sains Islam Malaysia
}

Noor Syamilah Zakaria

Department of Counselor Education and Counseling Psychology, Universiti Putra Malaysia

Email: syamilah@upm.edu.my

\section{Dini Farhana Baharudin}

School of Human Resource Development and Psychology, Universiti Teknologi Malaysia

\section{Steven Eric Krauss}

Department of Professional Development and Continuing Education, Universiti Putra Malaysia

\section{Zainal Madon}

Department of Human Development and Family Studies, Universiti Putra Malaysia

\section{Neerushah Subarimaniam}

Department of Counselor Education and Counseling Psychology, Universiti Putra Malaysia

\begin{abstract}
Disaster survivors are individuals who are literally survived in the aftermath of disaster situations. They are dislocated from their affected homes to evacuation centers; and forced to leave behind all belongings. Due to the characteristics of disasters that are sudden and catastrophic, disaster survivors often experience substantial symptoms of distress and respond with psychological and psychosocial reactions. This qualitative research was conducted using a descriptive phenomenological study approach to explore, understand, and describe the experience of counselors during natural disasters in Malaysian. The authors were the primary instrument for data collection and analysis. Data included field notes and individual semi-structured in-depth interviews. The authors developed coding categories using ATLAS.ti. The themes that emerged were refined, and became the major and subthemes for this research. This research found that the experience gained from the disaster
\end{abstract}


survivors during the disaster situations has developed the understanding and addressing the complexity of satisfying disaster survivors' critical needs during natural disasters. It was also informed that providing crisis support during natural disaster has brought plethora of experiences and knowledge that should be shared with other counselors in Malaysia.

Keywords: Counselors' Experience, Disaster Survivors, Natural Disasters, Descriptive Phenomenology

\section{Introduction}

Disaster survivors are individuals whom are literally survived in the aftermath of a disaster situations and they are dislocated from their affected home to evacuation centers; and forced to leave behind all their belongings (Sommers-Flanagan, 2007). However according to Wahlstrom (2010), due to the characteristics of all disaster that are sudden and catastrophic, disaster survivors often experience substantial symptoms of distress and psychosocial disruption and will respond with psychological reactions. The disaster survivors may think they have no control over anything and therefore feel helpless with their thinking and feeling are interconnected (Becker et al., 2008).

Understanding and addressing the complexity of satisfying disaster survivor's needs are critical during a disaster. In any disaster either man-made or natural, the victims or survivors experience suffering from many causes including bereavement from the loss of family members and friends, fear of dying, community destruction, social unrest, physical injuries, mental health problems such as posttraumatic stress disorder (PTSD), loss of livelihood, famine, migration, and even armed conflict (Barnes, 2006; Krishnaswamy et al., 2012). Therefore, the ability to provide crisis intervention and psychological support within all the challenges faced during the wake of natural disaster is very helpful in easing the burden faced by the disaster survivors. Thus, the purpose of this qualitative research was to conduct a descriptive phenomenological study to explore, understand, and describe the experience of counselors who provide crisis intervention and psychological support to disaster survivors during natural disaster in Malaysia. The knowledge gained from the understanding of experience can be used as a benchmark and guideline for their future preparedness so that it will not affect their personal and professional life.

This descriptive phenomenological research also sought to explore all the experience through detailed and in-depth data collection process, involving multiple sources of information. The data were gathered from individuals' in-depth interview transcripts and relevant documents including counselors' notes and pictures of crisis intervention and psychological support activities.

\section{Natural Disaster Situations in Malaysia}

Natural disaster are defined as ecological phenomenon that can happen suddenly without notice or awareness, and require immediate external assistance of humans to assess the needs of the disaster and the population affected (Simmons, 2010). Counselors are in a unique position to engage in disaster relief efforts because of their values and training, particularly around work with diverse clients (Bowman \& Roysircar, 2011).

The Malaysian National Security Council (MNSC) Directive 20 (Majlis Keselamatan Negara, 2012) defines disaster as "an emergency situations of some complexity that will cause the loss of lives, damage property and the environment, and hamper local social and economic activities" (p.2). Within other perspective, natural disaster are defined as 
catastrophic events resulting from natural causes such as floods, landslides, and mudslides; over which man has no control (Ibrahim \& Fakhru'I-Razi, 2006). Within the first decade of the second millenniums, Malaysians have been given tremendous experience on natural disaster. As Ibrahim and Fakhru'l-Razi (2006) further elaborated their findings on clustering the disaster types in Malaysia, they concluded that natural disaster were 49 percent of total disaster in Malaysia whereby most of the natural disaster were resulted from heavy rains (floods) and landslides, which were 26 percent of it.

Within the past decade, the process of giving crisis intervention during natural disaster solely depends on the anchorage of counselors and social workers from the Malaysian Department of Social Welfare (DSW). The Department Social Welfare (DSW) was established in April 1946. It has evolved through many phases in fulfilling its role in national development. From its involvement with major problems caused by the Second World War, the role and functions of the department have expanded to include prevention and rehabilitation services of social issues and community development. As one of the government agencies with a vital role in social development, it has been placed under several Ministries. The Counseling Division of DSW was established on 1 April 1998 following the restructuring of the department through the Public Service Department directive. This section was originally called Counseling Division. The division created because of formulation and enforcement of Counselors Act 1998 (Act 580). In the preliminary stages of the first two years of implementation of the Act, this section is headed by a director that also serves as Registrar of Counselors and became the first Secretary of the Board of Counselors. Through their Community Psychology Branch, the Counseling Division of DSW has been planning, developing, implementing, coordinating and monitoring the interventions related to functionality of disaster and crisis victim at the headquarters, state, county and institutions level (Jabatan Kebajikan Masyarakat Malaysia, 2016). According to the Malaysian National Security Council (MNSC) Directive 20, Department Social Welfare as part of the main government assistance and recovery agency are in charge of providing welfare assistance, counseling services (including crisis intervention and psychological support), logistics and other related support in disaster management (Majlis Keselamatan Negara, 2012).

\section{Research Objectives}

Based on the purpose of this study, the objectives of this research were to explore and describe the experience of counselors with disaster survivors during natural disaster in Malaysia.

\section{Research Questions}

The research questions have emerged from my own inquiry: As little is known regarding the issue, this research sought to develop a substantive description from the data gathered. As such, the empirical area for this research is focused on the phenomenon of counselors who had experience providing crisis intervention and psychological support with disaster survivors during natural disaster. This research has answered the following research questions: What are the experiences of counselors with disaster survivors during natural disaster in Malaysia?

\section{Materials and Methods Research Design}

This research employed a constructivist paradigm with a focus on the descriptive phenomenological method. Thus, in this research, the counselors' lived experience, the 
essence of their experience, and what is important in their experience can best be explored using this descriptive phenomenological method, where counselors' can express their point of view in their own words about the meaning of their experience with disaster survivors during natural disaster.

\section{Descriptive Phenomenology Approach}

A phenomenological analysis does not intend to explore or discover causes; instead, the focus is to clarify the meanings of phenomena and describe the meaning of their lived experience for several individuals within a phenomenon. Thus, phenomenologists focus on describing similarity of all participants' experience on a phenomenon and reduce individual experience with a phenomenon to a description of the universal essence (Van Manen, 1990; Creswell, 2006; Penner, 2008). A descriptive phenomenological study is conducted for the researcher to understand the descriptions of the experience of counselors with disaster survivors during natural disaster. Descriptive phenomenology involves direct exploration and analysis of a phenomenon to arrive at a description of the lived, or subjective, experiences of the participant (Penner et al., 2012, p. 564).

Van Manen (1990) added that qualitative researchers will identify a phenomenon as an "object" of human experience. This human experience may be phenomena such as insomnia, being left out, anger and grief (Moustakas, 1994). Experience with disaster survivors during natural disaster can also suits up to this type of human experience phenomenon. The researcher then collects data from persons who have experienced the phenomenon (in the case of this study-Malaysian DSW counselors) and develops a composite description on the essence of the experience for all the individuals. This description consists of "what" they (the counselors) have experienced and "how" they (the counselors) experienced it (Moustakas, 1994).

Specifically discussing a design that suits this research, descriptive phenomenology has been chosen as it involves direct exploration of experience with disaster survivors during natural disaster and analysis of a particular phenomenon to arrive at a description of the lived, or subjective, experience of the participant (Penner et al., 2012). This type of approach is used when little is known about an issue with disaster survivors during natural disaster, and the aim of the research was to explicate and understand the phenomenon of interest from the perspective of those counselors who were directly involved in it (Streubert \& Carpenter, 2011). Given the descriptions and concept of research conducted on exploring the experience of counselors with disaster survivors during natural disaster in Malaysia, a descriptive phenomenological approach is justified to this research. The design of this research has adapted the procedures illustrated by Moustakas (1994), consist of (1) identifying a phenomenon to study - for this research the phenomenon is the experience of counselors during the immediate responses and the experience with disaster survivors are among other elements that being experienced by these counselors; (2) bracket out one's experience (in this research, as the researcher, I am bracketing my experience as a counselor on providing crisis intervention - it means that I did not in any way influencing the research participants on their sharing of experience), and collecting data from several persons (counselors) who have experienced the phenomenon; (3) analyze the data by reducing the information to significant statements or quotes and combines the statements into themes; and (4) develop a textural description of the experience of the persons (what participants have experienced), a structural description of their experience (how they experienced it in terms of the conditions, situations, or context), and a combination of the textural and structural 
descriptions to convey an overall essence of the experience.

To fully describe how the participants, view the phenomenon, I have bracketed out, as much as possible, my own experience. Prior to data collection process, I have involved in the crisis interventions of the aviation disaster in Malaysia. The incidents were on the disappearance of Malaysia Airlines flight MH370 and the shooting down of Malaysia Airlines flight $\mathrm{MH17}$. Although it was not considered as natural disaster situations, but the experience of providing crisis intervention to the next of kin was somehow can be portrayed within a similar framework of providing help in a crisis with disaster survivors.

Bracketing or epoche is the first step in "phenomenological reduction," the process of data analysis in which the researcher sets aside, as far as is humanly possible, all preconceived experience to best understand the experience of participants in the research (Moustakas, 1994). Descriptive phenomenology emphasizes on the basic strategy of phenomenological reduction to "reduce" the world from how it is viewed naturally, that is where knowledge is held with judgment to a world of pure phenomena (Penner, 2008). Bracketing is done when the researchers set aside their experience, as much as possible, to take a fresh perspective toward the phenomenon under examination. Moustakas (1994) admitted that this state of bracketing is seldom perfectly achieved. However, Creswell (2007) noted that researchers who embrace this idea when they begin a project by describing their own experience with the phenomenon and bracketing out their views before proceeding with the experience of others. It is a process of not allowing the researcher's meanings and interpretations or theoretical concepts to enter the unique world of the participants. Efforts has been made putting aside my repertoires of knowledge, beliefs, values, and experience to accurately describe the participants' life experiences. Data were collected from the individuals (counselors) who have experienced the phenomenon.

In using a descriptive phenomenological inquiry approach to explore the experience of counselors with disaster survivors during natural disaster in Malaysia, I have put every effort to set aside personal biases and previous knowledge on it either from my personal crisis interventions experience or from my readings within the literature. Preconceptions about the experience of counselors with disaster survivors during natural disaster were documented prior to the onset of this research within my preliminary study. The process of bracketing was ongoing, and it has been employed throughout the research.

\section{Subjects of The Study}

Smith (2008) asserted that qualitative researchers usually try to find a homogeneous sample, for which the research question will be meaningful. "Participants are selected on the basis that they can grant access to particular perspectives on the phenomena understudy" (Smith, 2009, p.49).

\section{Sampling Design}

As the research aimed to obtain an in-depth understanding of counselors' experiences, a purposive sampling has to be done to find a more closely defined group for whom the research question will be significant (Smith \& Osborn, 2008). Using purposive sampling, researchers select individuals for study participation based on their particular knowledge of a phenomenon for the purpose of sharing that knowledge (Penner, 2008). This approach enables the researcher to obtain "rich information" in which the participants could reveal the answer for the phenomenon of interest (Patton, 2002). Penner (2008) also asserted that this is an appropriate method to select the participants for a study using a descriptive 
phenomenological approach because the aim is to understand and describe a phenomenon from the perspective of those who have experienced it. Counselors who have experience in conducting crisis intervention of natural disaster were chosen to explore the phenomenon within their experience. It is assumed that the longer these counselors have served as crisis responders, the more of experience they have gained with the phenomenon. For inclusion in the research, the counselors were chosen from the lead agency that plays the key role when the nation is faced with natural disaster.

During natural disaster in Malaysia, Malaysian Department of Social Welfares (DSW) is the lead agency which provides the assistant on crisis interventions. The DSW counselors will be the first to arrive at the scene when the natural disasters struck the nation. The process of giving crisis intervention during natural disaster solely depends on the anchorage of counselors and social workers from the Malaysian Department of Social Welfare (DSW). According to the Malaysian National Security Council (MNSC) Directive 20, Department Social Welfare as part of the main government assistance and recovery agency are in charge of providing welfare assistance, counseling services (including crisis intervention and psychological support), logistics and other related support in disaster management (Majlis Keselamatan Negara, 2012). Therefore, the DSW counselors are the most suitable research participants to be chosen for exploring their experience of providing crisis intervention in natural disasters in Malaysia. All the chosen research participants are counselors with proper academic qualification within their first degree or post-graduate degree from respective local universities.

\section{Sampling Strategy}

The counselors interviewed for this research were chosen from those who have at least one experience providing crisis intervention during any natural disasters in Malaysia. The DSW counselors have rich experience of providing crisis intervention during natural disaster as they are not only looked after their own district, but they were also deployed to help other districts or states during natural disasters situations. There are no minimum lengths of experience stated for this research. Although it is assumed that time frames will determine a counselor's experience working as crisis responder, the impact gains from it has no differences (Hesse, 2002; Jacobson, 2012). To capture a range of experience providing crisis intervention during natural disaster, attempts have been made to recruit both male and female counselors. Nevertheless, the selections of counselors were depending on the permission given by Director General of DSW.

\section{Sample Size}

The guiding principle on estimating adequate sample size is directly related to the concept of saturation (Mason, 2010; Marshall et al., 2013) All of the phenomenological studies identified had at least six participants, as suggested by Morse (1994): while just over two thirds identified (68\%) fell within Creswell (1998) suggested range of five to 25 (Mason, 2010). For this study, at the point of saturation, seven counselors were interviewed.

\section{Rigor and Trustworthiness of the Research}

The following discussion addresses the issues of trustworthiness and rigor, and the strategies utilized to establish the quality and credibility of this research. Given my experience on crisis intervention that has been explained earlier, issues of rigor and the need to avoid bias are very important. To ensure all biases are avoided, I have carefully selected the 
questions during interview practices, probing was done within the participants frame of references without addressing my value into their description of experience. A consistent inscription of a reflective journal and field note entries were done during the data gathering process, as well as debriefing of concerns with the participants, doubts, and issues in relation to data collection and data analysis. In addition, I have also used bracketing to restrain my belief and attitudes toward the description given by the participants as it has been explained earlier.

\section{Inter-rater Reliability Coefficient}

This study is based on coded in-depth semi structured interview transcripts. Interrater reliability is often referred to in quantitative studies and generally perceived as a means of verifying coherence in the understanding of a certain topic (Marques \& Mccall, 2005). By using interrater reliability as a solidification tool, the interrater could become true validators of the findings of the qualitative study, thereby elevating the level of believability and generalizability of the outcomes of this type of study (Marques \& Mccall, 2005). The importance of rater reliability lies in the fact that it represents the extent to which the data collected in the study are correct representations of the data measured.

For the interrater reliability coefficient process, the raters were given a list of sub-themes from the data analysis together within its definitions. The raters later have given their agreement on the sub-themes. The agreements were later calculated using Cohen's kappa coefficient. Cohen's kappa coefficient $(\mathrm{K})$ is a statistic which measures inter-rater agreement for a qualitative study. It is generally thought to be a more robust measure than simple percent agreement calculation, as $\mathrm{k}$ considers the possibility of the agreement occurring by chance. Calculation of Cohen's kappa coefficient may be performed according to the following formula:

$\mathrm{K}=\mathrm{fa}-\mathrm{fc}$

$$
n-f c
$$

Whereby,

$\begin{array}{lll}\mathrm{K} & = & \text { coefficient value } \\ \mathrm{fa} & = & \text { the proportion of observations in agreement } \\ \mathrm{fc} & = & \text { the proportion in agreement due to chance } \\ \mathrm{n} & = & \text { total unit tested for agreement }\end{array}$

The $f a$ value gathered from rater no. 1 was 20 , rater no. 2 was 22 , and rater no. 3 was 20 . $f c$ value was 11 (50\% of agreement due to chance). The value of $n$ is 22 coding analysis unit. 
Table 1. Calculation of Kappa coofiecient agreement value between raters

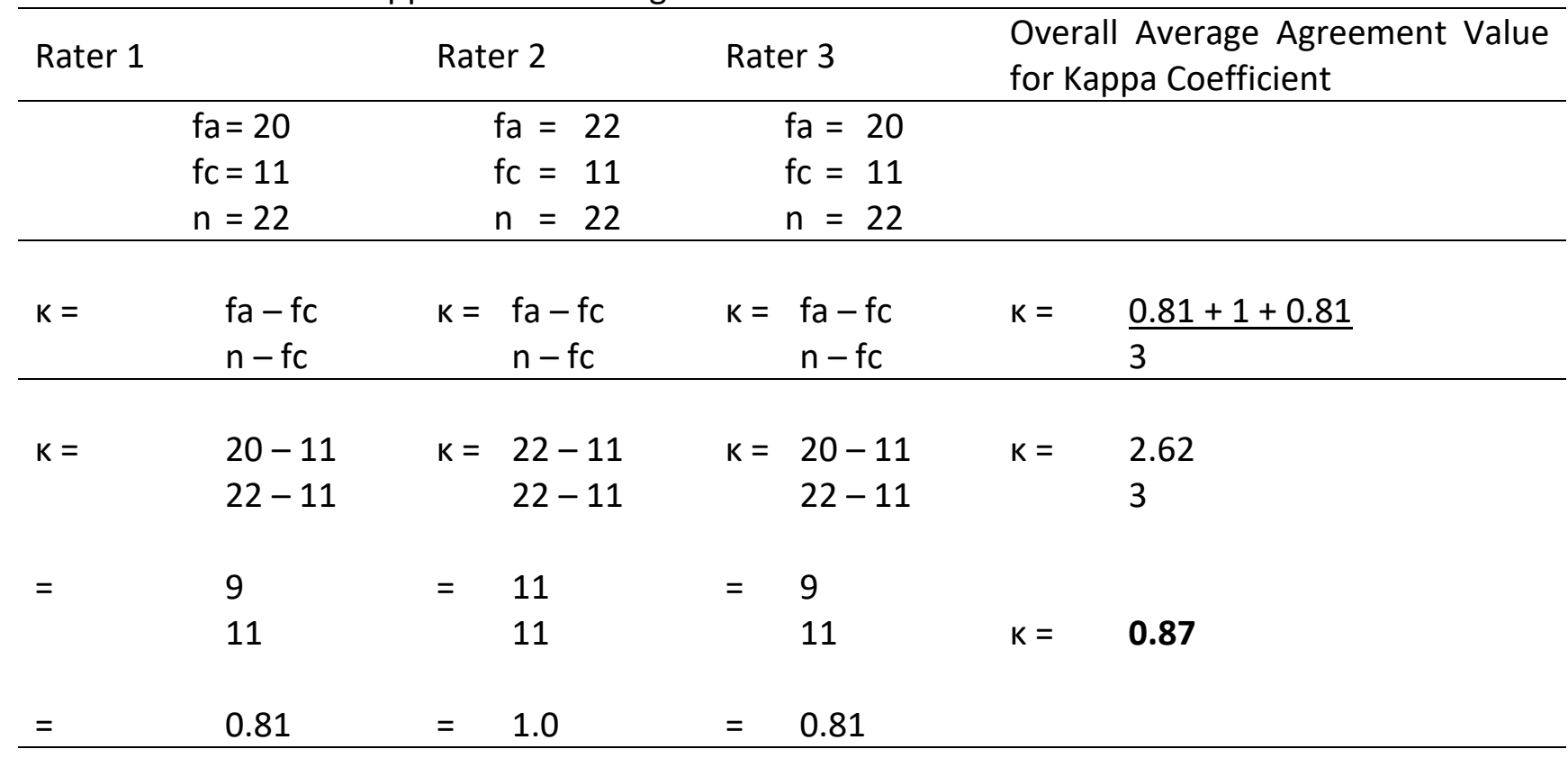

The Kappa agrement value is 0.87 .

Cohen Kappa Level of agreement scale: 0.87 = Strong level of agreement.

Table 2. Interpretation of Cohen's kappa

\begin{tabular}{|c|c|c|}
\hline Value of Kappa & $\begin{array}{ll}\text { Level of } \\
\text { Agreement }\end{array}$ & Percentage of Data that are Reliable (\%) \\
\hline $0-.20$ & None & $0-4$ \\
\hline $.21-.39$ & Minimal & $4-15$ \\
\hline $.40-.59$ & Weak & $15-35$ \\
\hline $.60-.79$ & Moderate & $35-63$ \\
\hline $.80-.90$ & Strong & $64-81$ \\
\hline Above.90 & Almost Perfect & $82-100$ \\
\hline
\end{tabular}

\section{Results}

Table 3. Themes and sub-themes derived from interview transcripts based on research question

\begin{tabular}{ll}
\hline $\begin{array}{l}\text { Research } \\
\text { questions }\end{array}$ & $\begin{array}{l}\text { What are the experiences of counselors with disaster survivors during natural } \\
\text { disaster in Malaysia? }\end{array}$ \\
\hline Themes & Sub themes \\
\hline \multirow{2}{*}{$\begin{array}{l}\text { The disaster } \\
\text { survivors }\end{array}$} & \begin{tabular}{l} 
1. Providing crisis intervention and psychological support \\
\cline { 2 - 2 }
\end{tabular} \\
\cline { 2 - 2 } & 2. Strength and motivation by the disaster survivors \\
\hline
\end{tabular}

\section{The Disaster Survivors}

Disaster survivors are individuals whom are literally survived in the aftermath of a disaster situations and they are dislocated from their affected home to evacuation centers; and forced to leave behind all their belongings (Sommers-Flanagan, 2007). However according to 
Wahlstrom (2010), due to the characteristics of all disaster that are sudden and catastrophic, disaster survivors often experience substantial symptoms of distress and psychosocial disruption and will respond with psychological reactions. The disaster survivors may think they have no control over anything and therefore feel helpless with their thinking and feeling are interconnected (Becker, Sapirstein, \& Weir, 2008).

Understanding and addressing the complexity of satisfying disaster survivor's needs are critical during a disaster. In any disaster either man-made or natural, the victims or survivors experience suffering from many causes including bereavement from the loss of family members and friends, fear of dying, community destruction, social unrest, physical injuries, mental health problems such as posttraumatic stress disorder (PTSD), loss of livelihood, famine, migration, and even armed conflict (Barnes, 2006; Krishnaswamy et al., 2012). Therefore, the ability to provide crisis intervention and psychological support within all the challenges faced during the wake of natural disaster is very helpful in easing the burden faced by the disaster survivors.

\section{Providing Crisis Intervention and Psychological Support}

Counselors who play vital roles of disaster mental health professionals often work with disaster survivors in the initial stages of the disaster recovery. Disaster recovery can be a complex and challenging process, when there are losses of lives and property as well as community displacement and sheltering can add additional stressors. Disaster survivors have disaster-specific needs such as medical needs as well as basic needs such as water and food that need to be attended to (Jordan, 2015, p.1). Disaster can also cause severe stress for individuals and community impairing their abilities to adapt and forcing them to rely heavily on their coping resources to continue functioning effectively in their life roles (Gunderson et al., 2012).

The counselors in this research described the experience on providing crisis intervention and psychological support. Counselors provided crisis intervention and psychological support for survivors with traumatic stress. During natural disaster situations, the counselors described that most of the population was affected with traumatic stress symptoms. The counselors also described that it is not only the disaster survivors, but the crisis responders are also prone to traumatic stress. The counselors reflected that they need to play vital roles in providing crisis intervention and psychological support to decrease the traumatic stress effects to the disaster survivors and crisis responders.

The counselors also described they provided psychological supports not only at the evacuation center, but they also provided door to door psychological and emotional supports. After the disaster survivors returned homes, the counselors reported that they have visited the survivors with the help of many other mental health responders. They also reported that with the help of their colleagues who were not facing any natural disaster situations, they shared their own traumatic stress experience for themselves to decrease their traumatic stress level. All the experience is shared as followed:

"... but for the elderly ... when we came to provide crisis intervention and psychological support and we wanted to see and talk to them, they cried ... when they cried, we will need time to let them process to recover from the feelings ... after that they felt happy..." (Ana)

"... we have crisis intervention... during that time when we went down to the evacuation center...first, when we enter the center... we made (an) observation, looking (around) ... (our) 
fear was (if there are) people that are inattentive or crying, we approach them first and did individual crisis intervention..." (Dayah)

“... after three days, the evacuation centers opened... we can do the crisis intervention, however, I took my own initiative that, when the evacuation center has opened, I straight away went there, to help the registration process and at the same time, I look (around), making observation on the behavior of the victims, considering their situations ... " (Suhai)

“... I tried to talk to them (the disaster survivors) ...providing crisis intervention and try to listen to their expression (of feelings and thought) ... since the process of registration, I had already listen to their expression... and it is more on listening to it (expression) ..." (Suhai)

"... when they (the disaster survivors) returned back their house respectively... we did our door to door (visits)... which means ... we go (around) knocking door to door... we found that ... at that time, indeed the need to (provide) crisis intervention and counseling for emotional (and psychological) are very demanded... which means (during) our visiting time, we are (limited) with our people (the counselors), we divide our (limited) groups into four teams and every team take (and provide service to) one district..." (Ana)

\section{Strength and Motivation by the Disaster Survivors}

Disaster does not only affect individuals, but it also affects the whole community and even the disaster responders. The effect to the counselors as the disaster responders may be presented within multiple reaction of cognitive, affective, and behavioral appearance that could weaken the ability of disaster responders to provide effective helps and support (Jacobs et al., 2011; Sweifach et al., 2013). Some people such as disaster survivors can cope effectively and mobilize their inner strengths, even though they viewed the psychological impact as intense. Nevertheless, many other individuals need to re-learn new resources and coping skills through skillful crisis intervention (Roberts, 2005).

The strength developed by some of the disaster survivors during the aftermath of the disaster event has reflected their ability to cope. The counselors have learned from the disaster survivors within their many loses, they are seemed as there was nothing happened to them. All these learning experience were described by the counselors. They have collected the experience during their services in providing crisis intervention during natural disaster and post-disaster psychological support so that they can build new strength from the disaster survivors experience. They told me that the experience has given great strength as it has also made a significant impact on them. The strength showed by the disaster survivors who faced impact of the disaster have made them (counselors) felt stronger, motivated them to pursue their responsibility despite all the challenges, and opened their mind into a better perspective of helping others. The counselors shared their experience as follow:

“... I am excited to see her strength ... “... Why I am not strong like her?" I wondered, and I asked myself, she is (the disaster survivor) 70 years old, she is strong even though with the losses of all her possessions (due to the massive flood) ... I have a dedicated support of my family, why can I not be stronger? The experience with her gave great strength for me..." (Azie) 
“...when I went for post-disaster (psychological support), it left me with a significant impact on my-self. Their experience that they shared, their strength has made my-self felt stronger. I have visited many houses especially in the Kelapa Laut Village..." (Azie)

"When things have become routine to me, when they shared their experiences, it is like the people's (experiences) motivated me and opened my mind. Their acceptance of the flood did give strength to me." (Erni)

\section{Facing Challenges on the Diverse Reactions of Disaster Survivors}

During the wake of natural disaster, the disaster survivors have reacted to the disaster impact in many ways. The diverse reactions of disaster survivors somehow have affected how counselors carried out their work in facing all the challenges given by the disaster survivors. During the disaster, counselors were anticipated to provide the best possible support and services while concurrently doing triage on the personal reactions and other challenges caused by the disaster (Sweifach et al., 2013).

The counselors described that the process of providing crisis intervention and psychological support during natural disaster has brought experience of facing challenges with diverse reactions from the disaster survivors. Most of the reactions are viewed as negative reactions from the survivors. They were portraying negative attitude, demanding, unsatisfied with many things and lack of cooperation. These negative reactions have in some ways given difficulties toward the process of crisis intervention and psychological support during natural disaster.

The counselors also said that with their negative attitudes, the disaster survivors always tend to refuse to cooperate and to involve with activities. They even fail to respond for any crisis intervention and psychological support activities which purposely were designed to help them ventilate from the pressure of facing the impact of traumatic stress. The counselors also shared their experience on the lack of cooperation by the disaster survivors as they described that there are some disaster survivors who are difficult to give cooperation. However, the counselors always continuously putting their responsibilities to the disaster response works.

The counselors also described that they must face challenges from some of the disaster survivors. It is part of the attitude shown by the disaster survivors themselves and the committee member (a group of disaster survivors who have been selected to help organizing the needs of disaster survivors at the evacuation centers) of the disaster survivors' population. The counselors shared that they witnessed events where the disaster survivors attacked the DSW crisis responders' due to dissatisfaction with many issues in the evacuation centers. The counselors did mention about the inability of disaster survivors to follow rules and procedures that were enforced in the evacuation centers. They reacted accordingly at that time using their own justification. The counselors described their experience on facing challenges on the diverse reactions of disaster survivors attitude as follow:

“... the attitude of disaster survivors and the attitude of committee members... not all, may be majority of them are ... but there are some (of the disaster survivors) that are fairly difficult to give cooperation..." (Mai)

“... So, for the moment, the complicated issue in carrying out our (counselors) duties during natural disaster is the (disaster survivors) attitude ..." (Mai) 
"... Yes ... the attitude of residents and the attitude of the committee ...not all, but majority ... but maybe there are some difficult to give cooperation. Because when we think of the circumstances at that time, we plan and continue to perform (our jobs) ... " (Mai)

The counselors also shared that they must face disaster survivors who demanded many things during these challenging moments. These demanding disaster survivors tended to provoke the crisis responders (including counselors) to fulfill their needs. The counselors described that they always believed on the need to handle these types of disaster survivors with full wisdom. With the disaster survivors intentionally tried to create conflicts, the inability to overcome the situations will spark a bigger 'flame' in the conflicts. That is why, as the counselors described, they need to provide information with proper explanation to all the disaster survivors at the evacuation center.

The counselors also experienced demanding disaster survivors as they claimed that the food given to them were not enough and looked like foods that are given to cats. They even threw the foods and shouted out to the crisis responders in responding to their dissatisfaction. The counselors also mentioned one example that the disaster survivor was asking for chicken rather than fish as they cannot stand the smell of fish. The disaster survivors' demanding issues focused on food preparation at the evacuation center. The counselors described their experience on facing challenges of demanding disaster survivors as follow:

“... then we bring down our officers (counselors) to provide them explanation wherever possible ... I do not know why ... when there is a crisis, there are times where the disaster survivors will deliberately provoked conflicts, demanding issues that are not supposed to be..." (Dayah)

"... at that time, I was doing (crisis) intervention from tent to tent. It was close to lunch time. Suddenly, I heard someone shouted: "the food is too little, and I got lots of children" ... If it is like this (the foods) you give to the cats, even the cats won't eat it. He threw it (the foods), the rice with food ... He said: "I cannot eat sardines, and the fishy smells make me want to throw up." They (disaster survivors) demanded to eat everything ... they wanted chicken..." (Ernie)

“... Normally here, the issue is ... the disaster survivors felt that it is not enough ... with the DSW supply... the supplies are limited ... the needs (is) to cater all ... but we try to make it enough to all the disaster survivors ... but some demands that, if there were 10 people in the family ... so the family should have two (sets) ... not only one (sets)... " (Suhai)

“... (The disaster survivors) demands to eat all sorts (of foods) ... (they) want chicken... The (foods) supply is sufficient; it is only that they did not prepare (meals with) meat and chicken every day... they prepared six meals per day" (Ernie)

Apart from that, the counselors also described stories of the disaster survivors who always demanded for good foods and the food supply must be sufficient to feed them all. The counselors experienced on the disaster survivors were unsatisfied and demanding for several types of foods rather than accepting the ones that have been supplied to them. The counselors also described that the unsatisfied disaster survivors threaten them to report on the foods to higher authority if they are (the counselor) reluctant to fulfill their demands. The 
counselors also described their experience on facing challenges of unsatisfied disaster survivors as follow:

"...Yes ... not satisfied ... it is always sardines he said. I said, "Is it always sardine?" Because of my knowledge, the DSW (have) brought in stocks of meat and chicken ... (the unsatisfied disaster survivor admitted): "Actually I do not even eat at the canteen ..." (Azie)

The counselors also shared the challenges in carrying out their duties due to the negative and uncooperative attitudes of the disaster survivors. These attitudes have made the disaster survivors felt that everything that was done to them is not enough. The disaster survivors wanted situations to be perfect at their point of views. They were reluctant to understand the limitation that the DSW were facing during natural disaster situations. Suhai and Erni shared their experience on getting cooperation from the disaster survivors as follow:

"... and (the) parents, they were just sitting at their places ... their area in the room (evacuation center) ... and just looking from a distance ... Sometimes they will approach the game (activities) area, the area where the activities are done ... but, they did not (want to get) cooperate ..." (Suhai)

"... When we went there (to provide crisis interventions), they (the disaster survivors) refused to cooperate. They tried to (give) trouble to us. They consider these things as a burden. We have many other problems ... They do not understand the real purpose of us (being there) to release (ventilate) them actually..." (Erni)

Nevertheless, within the diverse reactions of the disaster survivors, the counselors also described about the positive reactions by disaster survivors; that in some way have reduced the burden of counselors providing crisis intervention during natural disaster. They were prepared within their mental and physical ability to face the consequences of the disaster. Suhai shared the experience as follow:

"... The reason was when the water came down from Tenom. So, they can estimate ... they are ready, preparing themselves ... packing things ... tidy their home, kept save whatever possible ... So, they are ready ..." (Suhai)

"... Yes ... stress ... the effect of that ... however, due to its common here, and they can prepare in advance, so, the destruction was not too much of it..." (Suhai)

\section{Conclusion}

This research was conducted with a research question that was to explore what are the experience of counselors with disaster survivors during natural disaster in Malaysia? It has later revealed the descriptions of experience with the disaster survivors. This research has clarified that the experience was personally and directly gained by the counselors within their service of providing crisis interventions during the wake of natural disaster and during postdisaster. It can be concluded that the experience with the disaster survivors has been portrayed and described by the counselors as invaluable and has helped them in building new strength from the experience. 


\section{Theoretical and Contextual Contributions}

The findings of this study add to the literature on disaster survivors of natural disaster. This study also highlighted that crisis intervention skills and multicultural ability play significant role in dealing with disaster survivors. Next, various challenges encountered by natural disaster survivors were identified. Within the experience with the disaster survivors during the disaster events and in terms of contextual contribution, it has revealed experience on providing crisis intervention and psychological support with the people who were involved in the disaster. This research has also highlighted the counselors experience from developing and building their positive mind and inner strength form the experiences. It can be concluded that the process of building inner strength and positive mind of the counselors were derived from the accumulation of narrative shared by the disaster survivors and the attitudes of the disaster survivors toward building their resiliency during the wake of natural disaster. The experience has also brought an insight to the counselors on the issue of diversified reactions arise from the disaster survivors' during natural disaster events. It can be concluded that there are needs for the counselors to have a dynamic crisis intervention skills and multicultural ability to be applied when intervening various disaster response situations from the disaster survivors.

\section{Implication for Policy}

The findings of this research can help the counselors to better understand and increase their knowledge from the experience as crisis responder providing crisis intervention and psychological support during the wake of natural disaster in Malaysia. This section discusses the implications for future policy in improving the service of crisis intervention and psychological support toward the best disaster risk reduction and disaster risk management (DRR/DRM) in Malaysia.

Within the findings derived from this research, the counselors have revealed their experience during the immediate response phase and the post-disaster situations. It has also revealed the experience of the counselors with the disaster survivors. The psychological preparation and holistic support needed by the counselors and the disaster survivors are also revealed.

Evidences described by the counselors from the experience with the disaster survivors, has shown that there's a loop hole on the existing policy that does not comply with a certain level of specific ability in handling the worst-case scenario disaster situations. Although there is a directive (Directive 20, Malaysian Security Council), it has shown that the directive is not totally been familiarize by all disaster responders especially the counselors as the second level disaster responders. According to a survey done by Izumi \& Shaw (2009), it is observed that the basic information and knowledge on the priorities and necessary tasks in disaster risk reductions have not been acknowledged sufficiently at local authorities level in Malaysia. Adding to that, Said et al. (2011) mentioned that the Directive 20 was not fully understood by all stakeholders and thus let to unsatisfactory inter agency communication and coordination.

Therefore, it should be made compulsory for the directive to be familiarized; and specific table top and field exercise must be done with the involvement of the crisis intervention and psychological support team rather than with only major focus on the first responder now. Specific and annually disaster relief and disaster risk reduction training must be organized at all levels of disaster risk management agencies; might it be the districts, states or national level. For that matter, toward focusing on crisis intervention and psychological support, agencies with huge pool of counselors such as the Department of Social Welfare, the Public 
Services Department, the Ministry of Education, the Ministry of Health, the Royal Malaysian Police and institutions of higher learning such as universities, polytechnics, community colleges, and privates colleges, should combine their effort in introducing a specific policy of allowing the involvement of their respective counselors to be in the 'field' during the wake of natural disaster. This policy should allow the National Disaster Management Agencies (NADMA) to centralize the effort of gathering all the counselors if major natural disaster occurs. For NADMA itself, there should be a specific department or division established to focus on the psychological disaster risk reduction and management.

The findings derived from this research has also provides insight that can help the counselors to consider these aspects in the development of crisis intervention and psychological support policy and modules especially for DSW and NADMA. Description from the experience with the disaster survivors, has also brought in the idea that the crisis intervention and psychological support modules can be developed to cater the multi-reaction of disaster survivors. The crisis intervention and psychological support modules and policy should also consist of procedures in managing and considering bureaucracy during the wake of natural disaster. Furthermore, the modules could be able to help counselors in mastering their crisis intervention and crisis management skills. A good modules and policy with a standardized operating procedure are vital in providing guidelines for crisis responder to follow in a disaster situations (Izumi \& Shaw, 2009; Izumi \& Shaw, 2009; Said et al., 2011). It is also could ease and help other interested parties (non-government agencies) that would always come to help in the wake of natural disaster.

\section{Implication for Practice}

The findings derived from this research have provides knowledge for practitioners (counselors) in the field of crisis intervention and traumatic stress studies to re-evaluate, relearn and reconstruct their practice to better serve the people in need during the wake of natural disaster. The knowledge gained can also be related in the practice of disaster mental health, disaster risk management and disaster risk reduction.

Evidences described from the immediate response of the disaster events, together with the experience with the disaster survivors, has shown that ethical consideration during the wake of natural disaster is something important to be considered due to the extreme situations of certain natural disaster. Critical incidents such as natural disaster have been described as producing more ethical uncertainty and require more diligent observance of practical guidelines. Geale (2012) asserted that disaster responders can be faced with unusual situations in which the professional ethics that apply in routine emergencies and health care situations may be tested. Therefore, to ensure a proper practice of ethical considerations are adhered during the wake of natural disaster, counselors and other disaster responder should be properly and carefully trained to practice their ethical consideration. Ethical guidelines are also important for those disaster response practitioners to acknowledge the 'do's' and 'don' $t$ ' during the wake of natural disaster. Even though counselors are properly trained with their own ethics of counseling practice, but it is only practical in a normal counseling setting. The ethical guidelines are still needed as it will help counselors to have a room of consideration due to many other unexpected factors that could arise within the wake of natural disaster situations.

This research has also demonstrated the important roles of counselors even though they are lined as second responder in the wake of natural disaster. They could also jump in as support to the first responder if the situations deem to do so (Spokane et al., 2011). This 
situation should be considered as important as in disaster situations, everyone should be prepared to expect the unexpected. Therefore, toward providing professional practitioner capability, counselors should also consider to be trained with at least basic first responder skills such as medical first aids and basic rescue skills. It will help the counselors to be prepared if there are needs for them to react as support to a first responder during the first level of crisis response. It could be a good practice if all Malaysia counselors could undergo such specific training or better, they can be members of the Persatuan Bulan Sabit Merah (Malaysia Red Crescent), or Agensi Pertahanan Awam Malaysia (Malaysian Civil Defence) or anything like these two organizations. The combinations of their crisis intervention and psychological support ability within medical first aid and basic rescue skill would made them a reliable crisis responder.

To uplift the ability in their practices together with the ability to master the crisis intervention and crisis management skills, the counselors should also consider on equipping themselves with specific crisis interventions skills such as specializing in skills of handling grief and loss or skills on handling traumatic stress for specific age groups (i.e., older adults and children). The counselors could also consider on advancing their knowledge on having specific certification such as Psychological First Aid, Spiritual First Aid, Professional Traumatic Stress Managers or Critical Incident Stress Management. By attending and advancing themselves to gained knowledges, the counselors are also helping themselves to acknowledge and to lessen their own personal impact and it can also build their positive mind and inner strength.

Furthermore, considering to the training, simulation and exercises, Malaysian counselor educator to should also extend their abilities in doing research and develops modules for crisis intervention and psychological support within the Malaysia framework. Training modules such as Self-Care or Professional Traumatic Stress Managers could provide such basic and advance training not only to the counselors, but also to the public as it will also develop their preparation of mind, emotion and professional attitude in the wake of natural disaster situations. The trainings could be co-organized by the universities with cooperation with NADMA or DSW.

\section{Research Limitations}

This research was focused only on counselors who serve the DSW. There may be a lot of counselors who possess or practice proper crisis intervention and crisis counseling, but they are not included in this research. The counselors were only obtained from this single organization which is the main contributor during any natural disaster crisis intervention service. They came from the lead agency that plays the most vital role whenever the nation is faced with natural disaster. During natural disaster in Malaysia, DSW is the main supporting agency that will provide the help especially on crisis interventions. DSWs' counselors will be the first to arrive at the scene from any other agencies. Therefore, the results of this research do not consist all type of counselors in the nation such as school counselors, institution of higher learning counselors, and counselors who serve the Ministry of Health and the Public Service Department.

\section{Future Research Recommendations}

The descriptive nature of qualitative research can be directed toward many opportunities for future research. This descriptive phenomenological inquiry investigated the experience of counselors in providing crisis intervention and psychological support during the wake of natural disaster. This research involved a small population of the DSW counselors. For this 
reason, I anticipate that a replication of this research in other institutions such as counselors within the Ministry of Health and school counselors, with comparable demographics to determine if comparable research findings exist, possibly institutions that provides the same services such as counselors in health institutions in Malaysia. Further studies can also be conducted from separate groups such as non-governmental agencies which also provide the same support.

Another opportunity for future research would be to conduct this research within other method of qualitative inquiry such as case study to investigate specific issues for specific states as the counselors as they learn, understand, experience, and apply crisis intervention and psychological supports skills using specifically design modules developed by DSW. As the findings of this research have contributed to the understanding of experience and knowledge of providing crisis intervention and psychological support during the wake of natural disaster, there is still a need to conduct further research on this area to improve understanding and appreciation of the process of psychological preparedness either for the counselors or the disaster survivors.

\section{References}

Barnes, J. (2006). Developing Disaster survivor resiliency- The home away from home. Disaster Prevention and Management, 15(2), 223-232. https://doi.org/10.1108/09653 560610659766

Becker, K., Sapirstein, G., \& Weir, J. (2008). Psychological support for survivors of disaster: A practical guide psychological support for survivors of disaster. IBM Corporation. https://collabfor children.org/wp-content/uploads/Trauma-Guide-from-IBM-AdultsEnglish.pdf

Bowman, S. L., \& Roysircar, G. (2011). Training and practice in trauma, catastrophes, and disaster counseling. The Counseling Psychologist, 39(8), 1160-1181. https://doi.org/10.1177/0011 000010397934

Creswell, J. W. (1998). Qualitative inquiry and research design: Choosing among five traditions. SAGE Publications.

Creswell, J. W. (2007). Qualitative inquiry and research design: Choosing among five approaches (2nd ed.). SAGE Publications, Inc.

Geale, S. K. (2012). The ethics of disaster management. Disaster Prevention and Management, 21(4), 445-462. https://doi.org/10.1108/09653561211 256152

Gunderson, J., Crepeau-Hobson, F., \& Drennen, C. (2012). Research to practice: A disaster behavioral health framework. Disaster Prevention and Management: An International Journal, 21(5), 572-583. https://doi.org/10.1108/096535612 11278707

Hesse, A. R. (2002). Secondary trauma: How working with trauma survivors affects therapists. Clinical Social Work Journal, 30(3), 293-309. https://doi.org/10.1023/A:1016049632545

Ibrahim, M. S., \& Fakhru'l-Razi, Ahmadun. (2006). Disaster types in Malaysia: An overview. Disaster Prevention and Management, 15(2), 286-298. https://doi.org/10.1108/0965356061065 9838

Izumi, T., \& Shaw, R. (2009). Roles of civil society in climate and disaster resilience of cities and local governments. Community, Environment and Disaster Risk Management (Vol. 6). Emerald. https://doi.org/10.1108/S20 40-7262(2011)0000006019

Jabatan Kebajikan Masyarakat Malaysia. (22 April, 2016). Department of Social Welfare Malaysia. http://www.jkm.gov.my/

Jacobs, S. C., Leach, M. M., \& Gerstein, L. H. (2011). Introduction and overview: Counseling 
psychologists' roles, training, and research contributions to large-scale disasters. The Counseling Psychologist, 39(8), 1070-1086. https://doi.org/10.1177/0011000010 392245

Jacobson, J. M. (2012). Risk of compassion fatigue and burnout and potential for compassion satisfaction among employee assistance professionals: Protecting the workforce. Traumatology, 18(3), 64-72. https://doi.org/10.1177/1534765611431833

Jordan, K. (2015). The Disaster Survivor' s Hierarchy of Needs: What Every Disaster Mental Health Worker Should Know (No. 95). http://www.counseling.org/k nowledgecenter/vistas

Krishnaswamy, S., Subramaniam, K., Indran, T., \& Low, W.-Y. (2012). The 2004 tsunami in Penang, Malaysia: early mental health intervention. Asia-Pacific Journal of Public Health/Asia-Pacific Academic Consortium for Public Health, 24(4), 710-718. https://doi.org/10.11 77/1010539512453261

Majlis Keselamatan Negara. (2012). Arahan No. 20 (Semakan Semula) Dasar dan Mekanisme Pengurusan Bencana Negara. Majlis Keselamatan Negara, Jabatan Perdana Menteri.

Marques, J. F., \& Mccall, C. (2005). The Qualitative Report The Application of Interrater Reliability as a Solidification Instrument in a Phenomenological Study The Application of Interrater Reliability as a Solidification Instrument in a Phenomenological Study. The Qualitative Report, 10(3), 439-462. http://nsuwo rks. nova.edu/tqr/vol10/iss3/3

Marshall, B., Cardon, P., Poddar, A., \& Fontenot, R. (2013). Does sample size matter in qualitative research?: a review of qualitative interviews in is research. Journal of Computer Information Systems, 11-22.

http://dx.doi.org/10.1080/08874417.2013.11645667

Mason, M. (2010). Sample size and saturation in phd studies using qualitative interviews. Forum: Qualitative Social Research, 11(3), 1-14. https://doi.org/10.17169/fqs11.3.1428

Morse, J. M. (1994). Designing funded qualitative research. In N. K. Denzin \& Y. S. Lincoln (Eds.), Handbook of qualitative research (pp. 220-235). SAGE Publications.

Moustakas, C. (1994). Phenomenological research methods. SAGE Publications, Inc.

Patton, M. Q. (2002). Qualitative research and evaluation methods. Qualitative Inquiry (3rd ed., Vol. 3rd). SAGE Publications, Inc.

Penner, J. L. (2008). Using phenomenology to examine the experiences of family caregivers of patients with advanced head and neck cancer: Reflections of a novice researcher. International Journal of Qualitative Methods, 7(2), 92-101.

Penner, J. L., McClement, S., Lobchuk, M., \& Daeninck, P. (2012). Family members ' experiences caring for patients with advanced head and neck cancer receiving tube feeding: A descriptive phenomenological study. Journal of Pain and Symptom Management, 44(4), 563-571. https://doi.org/ 10.1016/j.jpainsymman.2011.10.016

Roberts, A. R. (2005). Crisis intervention handbook: Assessment, treatment and research (3rd ed.). Oxford University Press.

Said, A. M., Ahmadun, F.-R., Mahmud, A. R., \& Abas, F. (2011). Community preparedness for tsunami disaster: a case study. Disaster Prevention and Management, 20(Mmd), 266280. https://doi.org/ 10.1108/09653561111141718

Simmons, L. M. (2010). Adolescent victims of natural disasters: A phenomenological study on the effects of lived experiences and behaviors displayed after a crisis. Capella University.

Smith, J. A. (2008). Qualitative psychology: A practical guide to research methods (2nd ed.). SAGE Publications Ltd. 
Smith, J. A., \& Osborn, M. (2008). Interpretative phenomenological analysis. In Qualitative psychology: A practical guide to research methods (2nd ed., pp. 53-80). SAGE Publications Ltd.

Sommers-Flanagan, R. (2007). Ethical considerations in crisis and humanitarian interventions. Ethics \& Behavior, 17(2), 187-202. https://doi.org/10.1080/105 08420701378123

Spokane, A. R., Inman, A. G., Weatherford, R. D., Kaduvettoor, A., \& Straw, R. (2011). Ecologically based, culturally concordant responding following disasters: The counseling psychologist's role. The Counseling Psychologist, 39(8), 1128-1159. https://doi.org/10.1177/0011 000010397933

Streubert, H. J., \& Carpenter, D. R. (2011). Qualitative research in nursing: Advancing the humanistic imperative (5th ed.). Wolter Kluwer Health Lippincott Williams \& Wilkins.

Sweifach, J., Linzer, N., \& LaPorte, H. H. (2013). A social worker's duty to care: The self-other dimension of disaster response. Traumatology, 19(3), 3-10. https://doi.org/10.1177/153476561 2441977

Sweifach, Jay, Linzer, N., \& Laporte, H. H. (2013). Traumatology A Social Worker's Duty to Care: The Self. Traumatology, 19(1), 3-10. https://doi.org/10.117 7/1534765 612441977

Wahlstrom, L. (2010). Disaster and recovery. Karolinska Institutet. 